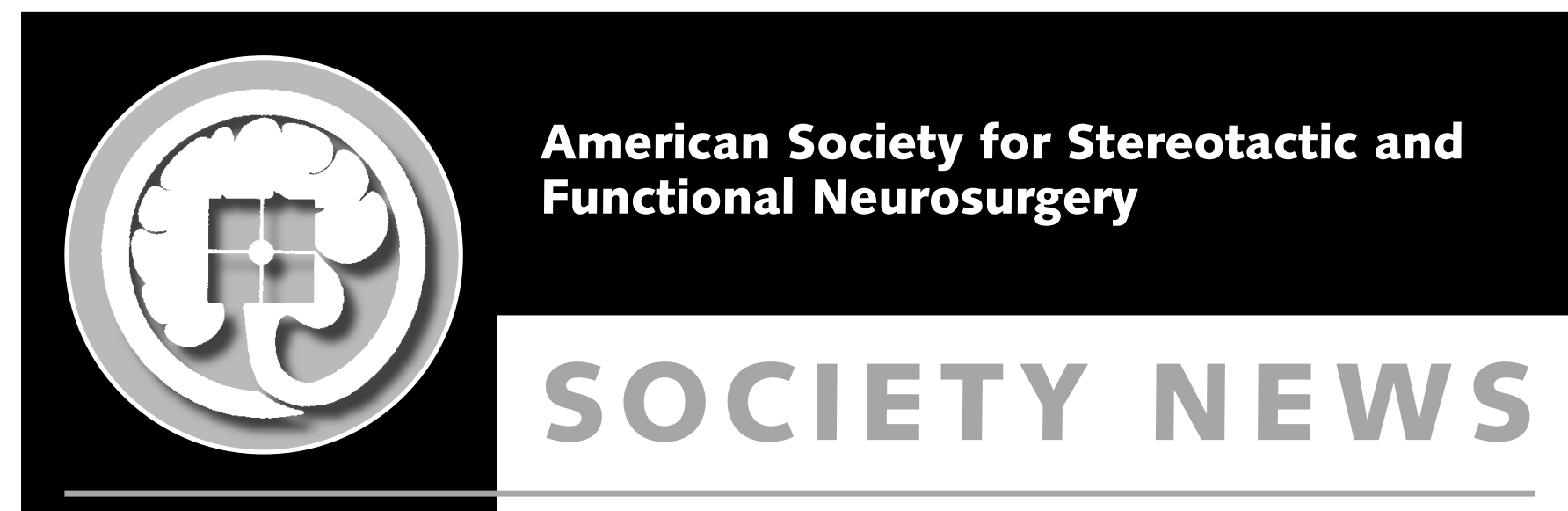

Officers 2004

President

G. Rees Cosgrove, Boston, Mass.

Past President

Douglas Kondziolka, Pittsburgh, Pa.

Vice-President

Andres Lozano, Toronto

Secretary and Treasurer Michael Schulder, Newark, N.J.

Executive Council

Richard D. Bucholz (2000-2004)

Ali R. Rezai (2000-2004)

Phillip A. Starr (2000-2004)

Robert J. Maciunas (2001-2005)

Robert Gross (2001-2005)

Ron Alterman (2002-2006)

Sam Hassenbusch (2002-2006)

Gordon H. Baltuch (2003-2007)

Jamie Henderson (2003-2007)

Konstantin Slavin (2003-2007)

Next Meeting

Biannual Meeting of the ASSFN

Topic: Neuromodulation

Cleveland, Ohio,

October 1-3, 2004

www.assfn.org

Membership

Membership information can be found on the ASSFN homepage: www.assfn.org

\section{President's Address}

G. Rees Cosgrove, MD

It is both a privilege and an honor to serve as the new President of the American Society of Stereotactic and Functional Neurosurgery especially when it yields such a unique opportunity to work with so many talented and committed individuals. First and foremost, on behalf of the entire membership, I would like to thank Pat Kelly, Andres Lozano and Doug Kondziolka for putting on the wonderful meeting recently in New York City. With over 300 registered participants, numerous corporate exhibitors and one of the classiest locations in all of New York City, this meeting was the most successful in the modern history of the Society. The material presented in the workshops, special lectures, oral presentations and posters was excellent. The number and quality of the submissions to the scientific organizing committee bodes well for future meetings and the health of our Society.

(Full report read on www.assfn.org) 